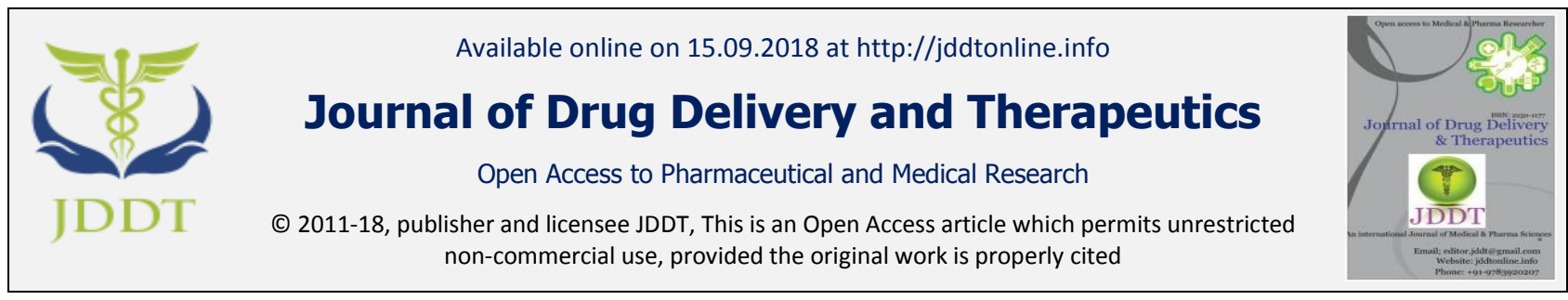

\title{
ANTIPLASMODIAL ACTIVITY OF CAESALPINIA CRISTA SEED EXTRACTS
}

\author{
M. Swapna Reddy ${ }^{\text {a,b }}$, B. Ramya Kuber $*^{\mathrm{a}}$ \\ ${ }^{\text {a }}$ Sri Padmavathi Mahila Visvavidyalayam, Tirupathi-517502, A.P, India \\ ${ }^{\mathrm{b}}$ Vaagdevi Pharmacy College, Bollikunta, Warangal, India
}

\begin{abstract}
Objective: To evaluate antiplasmodial activity of Caesalpinia crista seed extracts

Methods: Antiplasmodial activity of the seed extracts of Caesalpinia crista against rodent malaria infections in chloroquine sensitive Plasmodium falcipuram strain was investigated, and oral acute toxicity of seed extracts of Caesalpinia crista was also evaluated.

Results: The findings of this study revealed significant $(\mathrm{P}<0.05)$ and dose dependent decrease in parasitaemia in the parasitized groups treated with varying doses of the extract $(50-200 \mathrm{mg} / \mathrm{kg}$ p.o.) in both suppressive and curative tests. There was also significant decrease in parasitaemia density in the chloroquine treated group. The alcoholic extract was found no toxicity in wistar rats and the oral LD50 was determined to be greater than $5000 \mathrm{mg} / \mathrm{kg}$.

Conclusion: Seed extracts of Caesalpinia crista extract possesses potent antiplasmodial activity and may therefore, serve as potential sources of new antimalarial agents
\end{abstract}

Keywords: Plasmodium falcipuram, Caesalpinia crista, Plant extracts, Phytochemicals, Toxicity tests, malaria.

Article Info: Received 26 July, 2018; Review Completed 22 Aug 2018; Accepted 25 Aug 2018; Available online 15 Sep 2018

\section{Cite this article as:}

Swapna Reddy M, Ramya Kuber B, Antiplasmodial activity of Caesalpinia crista seed extracts, Journal of Drug Delivery and Therapeutics. 2018; 8(5):354-357 DOI: http://dx.doi.org/10.22270/jddt.v8i5.1880

\section{*Address for Correspondence:}

Dr. B. Ramya Kuber, M.Pharm, Ph.D, Associate Professor, Institute of Pharmaceutical Technology, Sri Padmavati Mahila Visva Vidyalayam (Women's University), Tirupati-517502, A.P, India.

\section{INTRODUCTION $^{1,2,4,5}$}

Malaria still remains one of the killer diseases plaguing Africa and other developing countries. The development and spread of drug resistant strains of the causative agent Plasmodium falciparum has limited the effectiveness of the currently used malarial drugs. This creates the need for new antimalarial drugs. Plants have over the years proved to be a good source of chemotherapeutic agents.

Caesalpinia crista (Caesalpiniaceae) is a large scandant prickly shrub found throughout the interior parts of India, Sri Lanka and West Indies. It is common in southern parts of India and is often grown as a hedge plant. Caesalpinia is a pantropical genus with 120-130 species, but has a complex taxonomic history. This plant has profound medicinal use and is proved to have adaptogenic activity, anthelmintic activity, antiinflammatory activity, antipyretic activity, analgesic activity, anti-amyloidogenic activity, antibacterial activity, antidiabetic activity, antifilarial activity, antioxidant activity, nootropic activity, immunomodulatory activity, hypoglycemic activity and hepatoprotective activity. The macro and microscopical features of the seed, leaf and flowers have been studied.

\section{MATERIALS AND METHODS}

\section{Plant collection and sample preparation}

Collection of plant part: The seeds of Caesalpinia crista were procured from local areas of Warangal, Telangana in the month of January, 2017 Seeds were authenticated and voucher specimen was deposited in 
Department of Botany, Kakatiya University, Warangal for further reference.

Preparation of extract: Dried seed kernels of Caesalpinia crista Linn. were taken. Seed coat was broken and testa was separated. The kernel was powdered and passed through sieve No. 40 and stored in an airtight container for the extraction. It was extracted with ethanol for $6 \mathrm{~h}$ in soxhlet assembly. The ethanolic extract was then concentrated on rotary evaporator. The residue was yellowish brown sticky mass.

\section{Phytochemical screening ${ }^{3}$}

The phytochemical screening of ethanolic seed extract of Caesalpinia crista was carried out to check the presence of chemical constituents like flavonoids, alkaloids, tannins, triterpenoids, coumarin glycosides and proteins using standard procedures of analysis (Harborne, 1973)

\section{Acute toxicity test ${ }^{6,7,8}$}

The LD50 of the seed extract was examined to determine the safety of the agent in rats, in vivo following OECD (2010) method. Dose levels used ranged from $10-5000 \mathrm{mg} / \mathrm{kg}$. The rats were observed for signs of toxicity such as salivation, stretching of the body, weakness, paw licking, respiratory distress, coma and death for $72 \mathrm{~h}$

.Animals: Wistar albino rats (120-150 g) of either sex were divided into five groups of six rats each (24 rats). Animals were housed under standardised animal house conditions like $12 \mathrm{~h}$ light/dark cycle, temperature $\left(24 \pm 1^{\circ} \mathrm{C}\right)$, relative humidity $(55-65 \%)$ in all the experiments. They had free access to pelleted food and water ad libitum. The animals were acclimatized to laboratory conditions for 1 week prior to experimentation. All the animal experiments were carried out in accordance with the guidelines of CPCSEA (Committee for the Purpose of Control and Supervision of Experiments on Animals) and study was approved by Institutional Animal Ethical Committee with registration no. 1663/PO/RE/S/12/CPCSEA. The animals were assigned to different groups to be treated in experiments according to their weight range.

\section{Parasite}

Chloroquine-sensitive Plasmodium falcipuram NK65 obtained from National Institute for Malarial Research (NIMR) New Delhi was used for the study.

\section{Infection of wistar rats with Plasmodium falcipuram}

All the wistar rats used for the study were inoculated intraperitoneally on day 1 with $1 \times 107 \mathrm{P}$. falcipuram parasitized erythrocytes obtained by suitable dilution with normal saline $(0.9 \%)$ of a donor infected mouse by cardiac puncture.

\section{In vivo antiplasmodial study ${ }^{9,10,11,12}$}

Suppressive study: This was the four-day suppressive study adopting the methods of Akuodor et al and David et al with slight modification. Thirty healthy albino wistar rats (male or female) were inoculated intraperitoneally with infected blood suspension $(0.2$
$\mathrm{mL}$ ) containing $1 \times 107$ NK65 Plasmodium falcipuram. After inoculation, the animals were grouped into 5 of 6 wistar rats per cage. The first 3 groups were treated with the extract under study (50, 100 and $200 \mathrm{mg} / \mathrm{kg}$, p.o.), while the last 2 groups were treated with the standard drug, chloroquine and normal saline $(10$ and $20 \mathrm{~mL} / \mathrm{kg}$, p.o.). The treatments were continued for $2 \mathrm{nd}, 3 \mathrm{rd}$ and $4^{\text {th }}$ day of the study. On the 5th day, thin films were made from the tail blood of each mouse. The films were allowed to dry, fixed in methanol, stained with Giemsa, and parasitaemia density was examined microscopically (CX 21, Olympus) by counting the parasitized red blood cells in 10 different field.

\section{Curative study:}

The curative potential of Caesalpinia crista seed extracts was evaluated following the methods of Akuodor et al and Peter et al with slight modification. Thirty wistar rats employed for this study were intraperitoneally inoculated with blood suspension (0.2 $\mathrm{mL}$ ) containing $1 \times 107$ Plasmodium falcipuram on day one. Seventy-two hours post-inoculation, the experimental animals were grouped and divided into 5 groups of 6 wistar rats per cage. Groups 1-3 were treated with the seed extract $(50,100$ and $200 \mathrm{mg} / \mathrm{kg}$, p. o. respectively). Groups 4 and 5 (positive and negative control) were treated with chloroquine $[10 \mathrm{mg} / \mathrm{kg}$ and normal saline $(20 \mathrm{~mL} / \mathrm{kg})]$, orally. Treatments were continued for days 4,5 and 6 . On the 7 th day, thin films were prepared from the tail blood of each mouse and dried. Thereafter, the air-dried films were fixed in methanol and stained with Giemsa. The parasitaemia density were later examined microscopically (CX 21, Olympus Corporation) by counting the parasitized red blood cells in 10 different fields. The mean survival time (in days) of each group was determined by finding the average time of wistar rats in each group over a period of 30 days.

\section{Statistical analysis}

Data obtained were expressed as mean \pm standard error of mean. Results were analyzed using one-way analysis of variance, differences between means were considered significant at $P<0.05$.

\section{RESULTS}

\section{Phytochemical test}

Phytochemical screening of the seed extracts of Caesalpinia crista showed the presence of flavonoids, tannins, saponins, terpenoids, steroids.

\section{Acute toxicity test}

There was no mortality recorded after oral administration of the alcoholic extract at $5000 \mathrm{mg} / \mathrm{kg}$. Hence the doses used (50, 100 and $200 \mathrm{mg} / \mathrm{kg}$, p.o.) were experimentally with in safe margin.

\section{Suppressive activity}

The alcoholic extract highly showed chemo-suppressive activity in a dose dependent manner. Doses used (50, 100 and $200 \mathrm{mg} / \mathrm{kg}$ ) exhibited 85\%, 88\% and 94\% Chemo-suppression of parasitaemia, respectively. The activity of the seed extract was significant $(P<0.05)$ 
when compared with the control. The standard drug chloroquine $(10 \mathrm{mg} / \mathrm{kg}$ ) caused $96 \%$ inhibition (Table

1).

Table 1: suppressive effect

\begin{tabular}{|l|l|l|l|}
\hline Drug & Dose (mg/kg) & Mean Parasitaemia (D5) & Suppression (\%) \\
\hline Control & 20 & $32.5 \pm 0.5$ & - \\
\hline Caesalpinia crista & 50 & $6.98 \pm 0.2$ & 78.5 \\
\hline & 100 & $3.93 \pm 0.3$ & 87.9 \\
\hline & 200 & $2.61 \pm 0.9$ & 91.9 \\
\hline Chloroquine & 10 & $1.8 \pm 0.2$ & 94.4 \\
\hline
\end{tabular}

Note: results are expressed as mean \pm standard error of mean. Significantly different from the control at $P<0.05(n=6)$.

Antiplasmodial suppressive activity of Caesalpinia crista
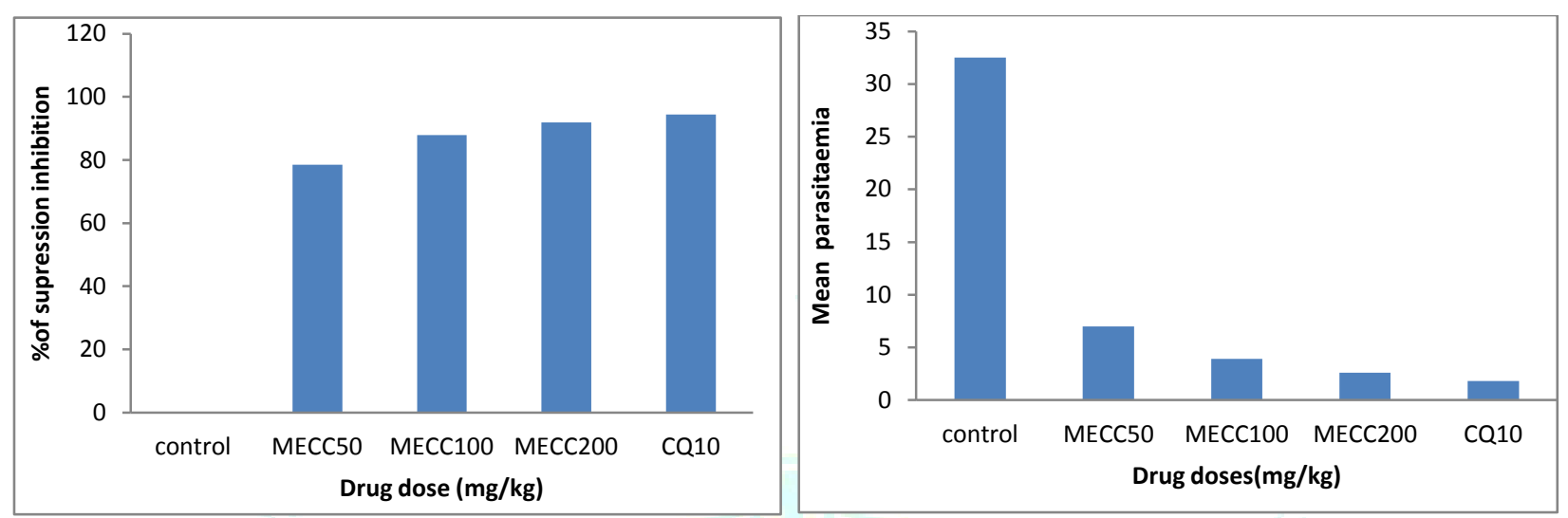

Figure 1: Antiplasmodial suppressive activity of Caesalpinia crista

\section{Curative activity}

The seed extracts significantly $(P<0.05)$ exhibited a dose dependent decrease in parasitaemia in both the extract treated and chloroquine treated groups. There was consistent increase in parasite density of the untreated group (negative control). Mortality was recorded in the untreated group on day 7 and by day 10 , all wistar rats in the group died. However, wistar rats in the groups treated with the extract survived beyond day 21 , and some wistar rats in $200 \mathrm{mg} / \mathrm{kg}$ survived the 30day observation period, while there was no mortality in the chloroquine treated group (Table 2).

Table 2: Curative effect

\begin{tabular}{|l|l|l|l|}
\hline Drug & Dose $(\mathrm{mg} / \mathrm{kg})$ & Parasite density (D3) & Parasite density (D7) \\
\hline Control & 20 & $32.4 \pm 1.2$ & $39.7 \pm 2.6$ \\
\hline Caesalpina crista & 50 & $30.2 \pm 2.4$ & $8.2 \pm 0.6$ \\
\hline & 100 & $29.4 \pm 2.6$ & $6.4 \pm 0.2$ \\
\hline & 200 & $31.6 \pm 2.2$ & $3.6 \pm 0.4$ \\
\hline Chloroquine & 10 & $30.5 \pm 1.4$ & $1.6 \pm 0.6$ \\
\hline
\end{tabular}

Note: Results are expressed as mean \pm standard error of mean. Significantly different from the control at $P<0.05(n=6)$

Table 3: Mean survival time of rodents receiving various doses of ethanolic extract of Caesalpinia crista

\begin{tabular}{|l|l|l|}
\hline Drug & $\begin{array}{l}\text { Dose } \\
(\mathrm{mg} / \mathrm{kg})\end{array}$ & $\begin{array}{l}\text { Mean survival } \\
\text { time (day) }\end{array}$ \\
\hline Control & 20 & $10.4 \pm 1.2$ \\
\hline Caesalpinia crista & 50 & $24.4 \pm 0.4$ \\
\hline & 100 & $26.6 \pm 0.2$ \\
\hline & 200 & $28.4 \pm 0.8$ \\
\hline Chloroquine & 10 & $30.0 \pm 0.0$ \\
\hline
\end{tabular}

Note: results are expressed as mean \pm standard error of mean. Significantly different from the control at a $P<0.05(n=6)$.

\section{DISCUSSION}

The seed extracts of Caesalpinia crista exhibited a high antiplasmodial activity in Plasmodium falcipuram infected wistar rats as shown by the percentage inhibition of parasite development. The alcoholic extract showed a high suppression of malaria parasites comparable to chloroquine, the standard drug. The seed extract showed a significant chemosuppressive effect, as the dose increased antiplasmodial activity also increased. Moreover, the observed antiplasmodial activity suggests that the seed extract of Caesalpinia crista can suppress parasite growth to undetectable levels in erythrocytes in a long term treatment as it is in traditional herbal 
medicine. It is imperative that herbal medicine preparations for claimed antimalarial agents are examined up to the point of knowing the level of suppression of parasite growth in red blood cells. The alcoholic seed extract of Caesalpinia crista also exhibited significant curative activity in the established infection. The observed antiplasmodial effect of the seed extract is consistent with the local use of the plant in traditional medicine against malaria, and indicative of its potential as a chemotherapeutic antimalarial drug. The antiplasmodial effect of the seed extract might be due to the presence of the secondary metabolites which have been variously implicated in antiplasmodial activity of numerous plants. High antiplasmodial activities on parasitaemia in this study are similar to the ones reported by Akuodor et al and Iwuanyanwu et al, whereby Caesalpinia crista leaf and stem bark extract at the dose of 400 and $600 \mathrm{mg} / \mathrm{kg}$ produced significant reduction of parasitaemia. The leaf extract of Caesalpinia crista also showed potent analgesic, anti-inflammatory and antipyretic properties in wistar rats and rats. Natural

\section{REFERENCES}

1. Kaushik NK, Bagavan A, Rahuman AA, Mohanakrishna D, Kamaraj C, Elango G. Antiplasmodial potential of selected medicinal plants from Eastern Ghats of South India. Exp Parasitol 2013; 134(1):26-62.

2. Banskota, A.H., F. Attamimi, T. Usia, T.Z. Linn, Y. Tezuka, S.K. Kalauni and S. Kadota. Novel norcassane-type diterpene from the seed kernels of Caesalpinia crista. Tetrahedron Lett., 2003; 44:6879-6882.

3. Harborne, A.J. Phytochemical Methods. Chapman and Hall, London, New York, Tokyo 1973; 1-33.

4. Kalauni, S.K., S. Awale, Y. Tezuka, A.H. Banskota, T.Z. Linn and S. Kadota. Cassane and nor cassane type diterpenes of Caesalpinia crista from Myanmar. J. Nat. Prod., 2004; 67:1859-1864

5. Swapna Reddy M, Ramya Kuber B. Evaluating the antiinflammatory potential of isolated constituents from seeds of caesalpinia crista .Journal of pharma Research 2017; 6( 2):77-78.

6. Organisation for Economic Co-operation and Development Guidelines on Acute Oral Toxicity. OECD guideline for testing of chemicals. Acute oral toxicity-acute toxic class method. OECD Guidelines for the Testing of Chemicals 2010; 1(4):1-14. products possessing the observed activities have been reported to provide relief for patients suffering from malaria attack. These findings support the ethnomedicinal use of this plant in the treatment of malarial and its associated symptoms. Furthermore, the active compounds observed in this study need to be identified. Some medicinal plants are known to exhibit antiplasmodial effect by either causing red blood cell oxidation or inhibiting protein synthesis depending on their phytoconstituents. However, the compounds observed in the seed extract may be acting singly or in synergy with one another to exhibit antiplasmodial activity. In conclusion, the findings of the present study have proved that the alcoholic seed extract of Caesalpinia crista possesses a strong antiplasmodial effect as observed in its ability to decrease parasitaemia density in the two models investigated. Further studies are ongoing in our laboratory to characterize and develop the actual compound(s) responsible for the observed antiplasmodial potential of this medicinally important plant.

7. OECD series on principles of good laboratory practice and compliance monitoring. Ann Institute Super Sanita 1997; 33(1):1-172.

8. NIH (National Institutes of Health). Guide for the Care and Use of Laboratory Animals. 8th ed. Bethesda MD: National Institutes of Health, 2011: 82-83.

9. David AF, Philip JR, Simon RC, Reto B, Solomon N. Antimalarial drug discovery: Efficacy models for compound screening. Nat Rev 2004; 3(6):509-520.

10. Akuodor GC, Anyalewech NA, Ikoro NC, et al. Evaluation of antiplasmodial activity of Berlina grandiflora leaf extract against Plasmodium falcipuram in wistar rats. Afr J Microbiol Res 2010; 4(21):2211-2214.

11. Mbah CC, Akuodor GC, Anyalewechi NA, Iwuanyanwu TC, Osunkwo UA. In vivo antiplasmodial activities of alcoholic extract of Bridelia ferruginea stem bark against Plasmodium falcipuram in wistar rats. Pharmaceutical Biology 2012; 50(2):188-192.

12. Iwuanyanwu TC, Akuodor GC, Essien AD, et al. Evaluation of antimalarial potential of aqueous stem bark extract of Caesalpinia crista (Bombacaceae). Eastern J Med 2012; 17(2):72-77. 